\title{
DIFERENÇAS DE GÊNERO E JUVENTUDE: UM ESTUDO A PARTIR DAS VIVÊNCIAS DE ESTUDANTES DE ENSINO MÉDIO DO MUNICÍPIO DE CAMPO MOURÃO-PR
}

\author{
Lucimar da Luz LEITE ${ }^{1}$ \\ Cristina Satiê de Oliveira PÁTARO ${ }^{2}$
}

RESUMO: O presente texto apresenta resultados de pesquisa cujo objetivo foi estudar em que medida as experiências, expectativas, escolhas e metas protagonizadas pelos jovens anunciam diferenças e desigualdades nas relações de gênero. Para tanto, fez-se uso de entrevistas semiestruturadas realizadas com 30 jovens estudantes na faixa etária entre 15 a 17 anos. A partir da análise dos dados, foi possível verificar que as influências exercidas pelas diferenças de gênero ficaram evidenciadas nos depoimentos dos jovens entrevistados, enunciando valores e práticas que enfatizavam o âmbito público para os jovens do sexo masculino e o âmbito privado para as jovens do sexo feminino. Dessa forma, são tecidas algumas considerações acerca dos processos educativos voltados para a juventude na contemporaneidade.

PALAVRAS-CHAVE: Juventude. Gênero. Processos educativos.

Nas últimas décadas, a temática da juventude vem ganhando especial relevância, retornando como foco das produções científicas após um período de ausência no cenário acadêmico. Ao tematizar os jovens, suas vivências e relações, grande parte das pesquisas traz contribuições para a compreensão das novas delimitações e novos desafios que as mudanças impulsionadas pelo cenário contemporâneo vêm trazendo às diferentes esferas da sociedade (PERALVA; SPOSITO, 1997). Deste modo, as experiências juvenis vêm evidenciando novas formas de sociabilidade, novas práticas e significados que se constituem nas relações que esses sujeitos estabelecem com o mundo, com o(s) outro(s), com as instituições. Ao mesmo tempo, nesse movimento - que se mostra complexo e não-linear -, é necessário compreender que, ao lado de mudanças e rupturas, outros sentidos e delimitações ainda permanecem e se perpetuam. É com este olhar que pretendemos, no presente texto, tecer breves considerações acerca das diferenças de gênero que se manifestam nas vivências juvenis.

Este trabalho nasce de inquietações procedentes de estudos e investigações que vêm sendo desenvolvidos nos últimos anos acerca de questões relacionadas à juventude, à

\footnotetext{
${ }^{1}$ Mestranda em Educação. UEM - Universidade Estadual de Maringá; Docente do curso de Pedagogia. Unespar - Universidade Estadual do Paraná. Campo Mourão - PR - Brasil. 87301-899 lukaluz24@hotmail.com.

${ }^{2}$ Docente do Programa de Pós-Graduação Interdisciplinar Sociedade e Desenvolvimento e do curso de Pedagogia. Unespar - Universidade Estadual do Paraná. Doutora em Educação. Campo Mourão - PR Brasil.87301-899 - crispataro@gmail.com.
} 
afetividade e às relações de gênero. A despeito do recorrente discurso de igualdade entre homens e mulheres na sociedade contemporânea, diversos depoimentos coletados junto a jovens estudantes de Ensino Médio e do Ensino Superior vêm sugerindo uma forte influência das diferenças - e desigualdades - de gênero nas experiências, nas relações, nas escolhas, expectativas e projetos de jovens em diferentes condições sociais ${ }^{3}$. Parte-se, portanto, da necessidade de melhor investigação de tais indícios, na intenção de compreendermos de modo mais aprofundado de que maneira as diferenças de gênero exercem influências e embasam significados nas vivências dos sujeitos jovens na contemporaneidade.

Assim, este texto busca desvelar de que modo as diferenças de gênero se manifestam nas vivências da juventude, com base em relatos dos próprios jovens. Tratase de discussão com base em resultados de pesquisa ${ }^{4}$ que teve como objetivo estudar e apontar os limites e/ou possibilidades que as diferenças de gênero (re)produzem no cotidiano, nas expectativas e projetos de vida dos jovens estudantes.

\title{
Juventude e gênero
}

O conceito de gênero é oportuno para analisar a organização social e as diferenças entre os sexos, buscando enfatizar o caráter social e relacional que permeia a definição do feminino e do masculino. Segundo Vianna e Ridenti (1998), gênero refere-se aos valores e atribuições sociais e culturais que são construídos e compreendidos em cada momento histórico, os quais estabelecem interferência de maneira positiva ou negativa na vida das pessoas. Nas sociedades, é possível verificarmos uma divisão baseada em padrões masculinos e femininos, a qual, derivada inicialmente das diferenças biológicas, passa a orientar a organização de toda a sociedade. Assim:

\begin{abstract}
A maioria das sociedades apresenta uma divisão de trabalho baseada em padrões masculinos e femininos. Essa divisão se constitui em torno de uma tendência praticamente universal de separação da vida social entre esfera pública, associada ao homem (à política e ao mercado de trabalho), e a esfera privada, doméstica, vinculada à reprodução e ao cuidado das crianças. (VIANNA; RIDENTI, 1998, p.97).
\end{abstract}

\footnotetext{
${ }^{3}$ Parte das discussões que emergem das investigações realizadas, bem como de considerações acerca da presente pesquisa podem ser encontradas em: Pátaro (2011, 2013); Luz e Pátaro (2010); Pátaro e Almeida (2011).

${ }^{4}$ Pesquisa de Iniciação Científica vinculada ao Núcleo de Pesquisa Multidisciplinar (NUPEM/Fecilcam), desenvolvida com apoio do PIBIC/CNPq.
} 
Para as autoras, os papéis e os comportamentos de homens e mulheres são definidos em termos recíprocos, e influenciados por fatores relacionados ao contexto histórico, social e cultural (VIANA; RIDENTI, 1998). Isso significa reconhecer que os papéis sociais associados ao gênero não são inatos ou universais e que, portanto, podem ser modificados.

As discussões sobre gênero, portanto, buscam superar a visão naturalizante das diferenças entre homens e mulheres, visão essa que acaba por atribuir às especificidades biológicas a inferioridade feminina e a dominação masculina, justificando desigualdades e injustiças presentes na relação entre homens e mulheres. A partir da utilização do conceito de gênero, a inferiorização das mulheres passou a ser questionada, e a relação entre homens e mulheres - caracterizada muitas vezes pela assimetria e pela hierarquização - passou a ser vista como permeada por relações de poder (VIANA; RIDENTI, 1998; SCOTT, 1994). Desse modo, de acordo com Viana e Ridenti (1998, p.97), “[...] apreender a dimensão da construção social do gênero através da história e nas diferentes culturas implica analisar as hierarquias e as relações de poder, questionando conceitos tratados como universais - homem e mulher - ou absolutos - igualdade e justiça".

Para Scott (1994), o gênero deve ser visto como elemento permeado pelas relações de poder, constitutivo de relações sociais e produzido a partir de processos conflitivos. Para a autora, os estudos de gênero implicam:

[...] enfatizar os significados variáveis e contraditórios atribuídos à diferença sexual, os processos políticos através dos quais esses significados são criados e criticados, a instabilidade e maleabilidade das categorias 'mulheres' e 'homens' e os modos pelos quais essas categorias se articulam uma em termos da outra, embora de maneira não consciente ou da mesma maneira em cada momento. (SCOTT, 1990, p. 25-26).

Diante dessas colocações, entendemos que, no processo de socialização e educação, as diferenças de gênero incutem nos sujeitos alguns valores, crenças e visões de mundo que perpassam papéis, escolhas, possibilidades e limitações, estabelecendo muitas vezes relações de desigualdade entre homens e mulheres (ARANTES; SASTRE; GONZÁLEZ, 2010; STACH-HAERTEL, 2009). Do ponto de vista biológico, as diferenças entre homens e mulheres se manifestam de forma evidente. $\mathrm{O}$ que se constata, no entanto, é que tais diferenças, inicialmente biológicas, transformam-se em desigualdades e discriminação, disseminadas historicamente pela sociedade e pela cultura 
(SASTRE et al., 1999; MORENO, 1999). A esse respeito, as considerações de Sastre et al. (1999) nos auxiliam ao apontar que:

\begin{abstract}
A força do costume faz com que se aceite com naturalidade que os textos escolares situem os homens e os meninos em um status social superior ao das mulheres e das meninas; faz com que os meninos sejam representados realizando atividades socialmente valorizadas enquanto se relegam às meninas atividades consideradas de segunda ordem. Também a força do costume faz com que os rapazes sejam estimulados a se identificar com modelos de comportamento agressivo que dificultam sua entrada no mundo das relações interpessoais e dos vínculos afetivos [...]. Existe, portanto, uma importante discriminação por razões de gênero. (SASTRE et al., 1999, p.19).
\end{abstract}

Moreno (1999) aborda a questão do androcentrismo na construção das representações de meninos e meninas, e ressalta a não neutralidade da Ciência, ao apontar que:

\begin{abstract}
A discriminação da mulher, as características negativas que lhe têm sido atribuídas têm-se apoiado frequentemente em concepções científicas [...], profundamente influenciadas por preconceitos ideológicos, dos quais a ciência atual não está isenta. É preciso contemplá-la, pois, com espírito crítico e transmitir este mesmo espírito aos jovens. (MORENO, 1999, p.22).
\end{abstract}

Durante milênios, o conhecimento que hoje assumimos por científico foi influenciado pelo chamado pensamento androcêntrico, pensamento esse que prega a superioridade masculina. Para a autora, o ensino escolar apresenta influências na formação da identidade de meninas e de meninos, interferindo nas representações dos papéis de gênero que são originários de um dado contexto histórico. Ainda que todos tenham acesso às mesmas explicações e realizem as mesmas tarefas, os ensinamentos apresentam diferenças, influenciando seus comportamentos e representações de gênero. Por meio desta formação, passada a ambos os sexos, o machismo torna-se paradigma não apenas de meninos, mas também de meninas que, educadas sob esta perspectiva, não são levadas a questioná-la e acabam por se sujeitarem às injustiças, aceitando, defendendo e transmitindo estas ideias. Perante esse quadro, uma das medidas a serem tomadas, de acordo com a autora, é transformar a educação e a forma como são passadas aos jovens as representações de gênero.

Para Fukuda, Brasil e Alves (2009), há diferenças históricas, socialmente constituídas pela humanidade nas suas vivências culturais, que conduzem a diferentes 
comportamentos e atitudes de homens e mulheres. Buscando apontar os fatores de risco e proteção relacionados ao gênero e que incidem sobre a juventude, as autoras apontam a existência de diferentes ciências e perspectivas epistemológicas que vêm a se ocupar dessa temática, o que evidencia a amplitude das influências que as diferenças de gênero exercem nos processos de socialização dos jovens. Para esses autores, além da diferenciação do sexo, são muitos os registros que enfatizam a desvalorização da mulher no que tange a vários aspectos sociais e econômicos, sendo alguns deles: o benefício público, o acesso a cargo políticos, a violência doméstica, a inserção no mercado de trabalho e outros.

Sposito (2003) também nos auxilia ao enfatizar a existência de uma discriminação por gênero. De acordo com esta autora, em 2001, 17,4\% das mulheres de 24 anos encontravam desempregadas, contra 9,3\% dos homens. Além disso, é possível apontar a diferença salarial existente entre homens e mulheres, sendo que as mulheres possuem salários inferiores aos dos homens. Para a referida autora, as mulheres tendem a assumir responsabilidades domésticas, ficando assim mais ausentes no mercado do trabalho. Deste modo, em sua pesquisa, identifica que:

[...] entre os jovens que não estudam nem trabalham, a maioria estava situada nos extratos mais pobres. Quase metade dos homens estava procurando trabalho, enquanto $48 \%$ das mulheres já tinham construído família (muitas delas chefe de família) e $58 \%$ já tinha filhos. As responsabilidades tradicionais do trabalho doméstico feminino explicariam em parte a ausência das mulheres jovens no mercado de trabalho e no sistema educacional. (SPOSITO, 2003, p.18).

Referindo-se à escolarização, Sposito (2003) aponta algumas diferenças em função do gênero. Ao analisar os dados do contexto brasileiro, afirma que as mulheres representam mais vantagens do que os homens, diante disso, argumenta:

\footnotetext{
A análise por sexo revela que, na média, as mulheres continuam em vantagem sobre os homens, vantagem que se ampliou entre $1991 \mathrm{e}$ 2000. Em termos da população brasileira com mais de 7 anos de idade, as mulheres tinham 0,2 ano de estudo a mais que os homens em 1991. Essa diferença se ampliou para 0,3 anos de estudo por ocasião do Censo 2000. Esse diferencial é ainda mais acentuado na população jovem, em que a diferença, que se manteve inalterada no período, é igual a 0,7 ano de estudo. (SPOSITO, 2003, p.14).
}

Em vista dos limites e possibilidades impostos pelas diferenças de gênero à juventude, compreendemos ser necessário verificar, com base nas experiências, 
preocupações, escolhas e expectativas relatadas pelos jovens, de que forma o gênero vem influenciando suas vivências e projetos de vida. Acreditamos que, ao dar voz aos próprios jovens, faz-se possível verificar as representações, os significados e os papéis que os sujeitos constroem em relação ao gênero, bem como as influências exercidas pelas diferenças de gênero nos diversos modos de ser jovem. A partir do exposto até o momento, destacamos a relevância do estudo que aqui relatamos, o qual pode, em última instância, servir de base para novas reflexões acerca dos processos de socialização e educação voltados às novas gerações, em busca de uma formação para a superação das desigualdades e injustiças, em especial relacionadas ao gênero.

\section{Vivências e expectativas de jovens estudantes}

A investigação que será apresentada a partir de agora teve como objetivo estudar de que forma as diferenças de gênero expressam limites e/ou possibilidades no cotidiano, nas experiências, expectativas, escolhas e metas protagonizadas pelos jovens estudantes. Para atingir aos objetivos propostos, foram analisadas entrevistas ${ }^{5}$ realizadas com 30 jovens de 15 a 17 anos, estudantes do Ensino Médio de um colégio da rede pública do município de Campo Mourão-PR. As entrevistas foram realizadas em duas etapas com cada um dos participantes. Na primeira etapa, o instrumento foi composto por várias questões referentes à identidade, interesses, atividades cotidianas, visão de mundo ideal e perspectiva de futuro dos jovens. A segunda etapa, realizada após um intervalo de 45 dias, objetivou retomar as colocações dos participantes, possibilitando a confirmação, reflexão e aprofundamento dos relatos iniciais.

A partir dos dados coletados, identificamos nos relatos dos jovens os episódios (momentos, espaços, relações e reflexões) que apresentam as influências das diferenças de gênero nas vivências dos jovens. Na metodologia do estudo, a análise dos relatos buscou enfatizar algo "[...] que o informante efetivamente presenciou, experimentou ou de alguma forma conheceu". (QUEIROZ, 1988, p.21). Os elementos, significados, implicações e/ou relações presentes nos relatos analisados, que subsidiaram os eixos de análise identificados, emergem, portanto, da leitura e releitura dos próprios dados analisados (MORENO et al., 1999).

A partir da análise dos dados, os resultados indicam evidentes diferenças em função do gênero dos participantes, as quais se traduzem em vários trechos dos relatos,

\footnotetext{
${ }^{5}$ As entrevistas analisadas foram coletadas por ocasião de investigação mais ampla, à qual esta pesquisa se vincula, atendendo a todos os critérios e procedimentos éticos exigidos para sua realização.
} 
sendo possível apontar semelhanças entre as vivências de jovens do mesmo sexo e diferenças quanto ao sexo oposto. Vejamos:

Eu acordo, agora eu aprendi a fazer café porque minha mãe está trabalhando e acorda primeiro que eu. Então eu tenho que me arrumar, vou ver uma coisinha ou outra, troco meu irmão dormindo, porque ele acorda estressadinho. Aí eu acordo ele, ele vai se arrumar come, a gente vem pra escola, na hora de sair eu o pego na escola. Então a gente vai embora. Eu chego em casa, faço almoço, vou limpar a casa. (Feminino, 16 anos).

Na $3^{a}$ e na $5^{a}$ eu faço curso de informática, arrumo a casa, lava roupa, faço comida, serviços de casa. (Feminino, 15 anos).

Tenho 16 anos e gosto de estudar, fazer cursos de informática, jogar bola, trabalho de garçom na pizzaria, sou torcedor do Santos, fanático. Trabalho todos os dias e folgo na quinta. (Masculino, 16 anos).

Acordo de manhã, tomo banho, venho pro colégio, volto, almoço. Tem dia que eu vou trabalhar com meu tio, tem dia que eu fico em casa, de $2^{a}$ e $6^{a}$ eu treino aqui no colégio. (Masculino, 17 anos).

Nos depoimentos acima, identificamos nos relatos femininos marcas explícitas da responsabilidade das jovens nos afazeres domésticos. Para as participantes, a realização das tarefas de casa parece ser algo determinado e transmitido a elas. Em contrapartida, os jovens do sexo masculino parecem dedicar mais tempo aos estudos, cursos, ao trabalho e ao lazer. Assim, enquanto as jovens privilegiam atividades voltadas para o âmbito privado, as atividades dos jovens do sexo masculino voltam-se para o âmbito público.

As considerações de Sastre et al. (1999) nos auxiliam na interpretação desses dados, ao apontar que os costumes que são atribuídos socialmente permitem que aceitemos com naturalidade que os homens situem-se em um status social superior aos das mulheres. Assim, no processo de educação e socialização, os meninos são em geral associados a atividades socialmente valorizadas, enquanto se relega às meninas atividades consideradas de segunda ordem, voltadas para a vida privada. Do mesmo modo, Vianna e Ridenti (1998) afirmam que há, socialmente, uma divisão baseada em padrões masculinos e femininos que passam a nortear a organização de toda a sociedade, separando a esfera pública - associada ao homem - e a esfera privada, doméstica, associada à mulher.

Ao questionarmos acerca das atividades que consideram que fazem bem (Das coisas que você faz, o que você diria que faz bem?), grande parte das jovens nos confirma, mais uma vez, a realização de tarefas voltadas para o âmbito doméstico. 
Apenas três jovens citaram estudos e cursos, as demais apontaram, em sua maioria, tarefas ligadas ao grupo doméstico. Podemos observar nos fragmentos a seguir:

[Das coisas que você faz, o que diria que você faz bem?] Arrumar a cozinha da minha casa. (Feminino, 16 anos).

[Das coisas que você faz, o que diria que faz bem?] Cozinhar. [É você que cozinha na tua casa?] É. [Todos os dias?] Todos os dias. (Feminino, 16 anos).

[Das coisas que você faz, o que diria que faz bem?] Acho que cuidar da casa, do meu irmão e estudar, nem tanto, mas... (Feminino, 15 anos).

[Das coisas que você faz, o que diria que faz bem?] Eu acho que o que eu sei fazer bem é cozinhar, limpar a casa. (Feminino, 15 anos).

Diante da mesma indagação, os jovens do sexo masculino tendem a referenciar atividades como: esporte, desenho, trabalho e, com grande ênfase, os estudos. Vejamos os trechos a seguir:

[Das cosias que você faz, o que você faz bem?] Estudar. [...] Matemática, química, física, educação física. (Masculino, 16 anos).

[Das coisas que você faz, o que diria que faz bem?] Ah, tudo. [Por exemplo?] Eu estudo, não falto na aula. (Masculino, 17 anos).

[Das coisas que você faz, o que diria que faz bem?] Trabalho, esporte. (Masculino, 17 anos).

O gráfico 1 sistematiza as respostas dadas pelos participantes a esta questão da entrevista:

Gráfico 1 - Categorias de atividades citadas, por sexo dos/as participantes.

Das coisas que você faz, o que diria que faz bem?

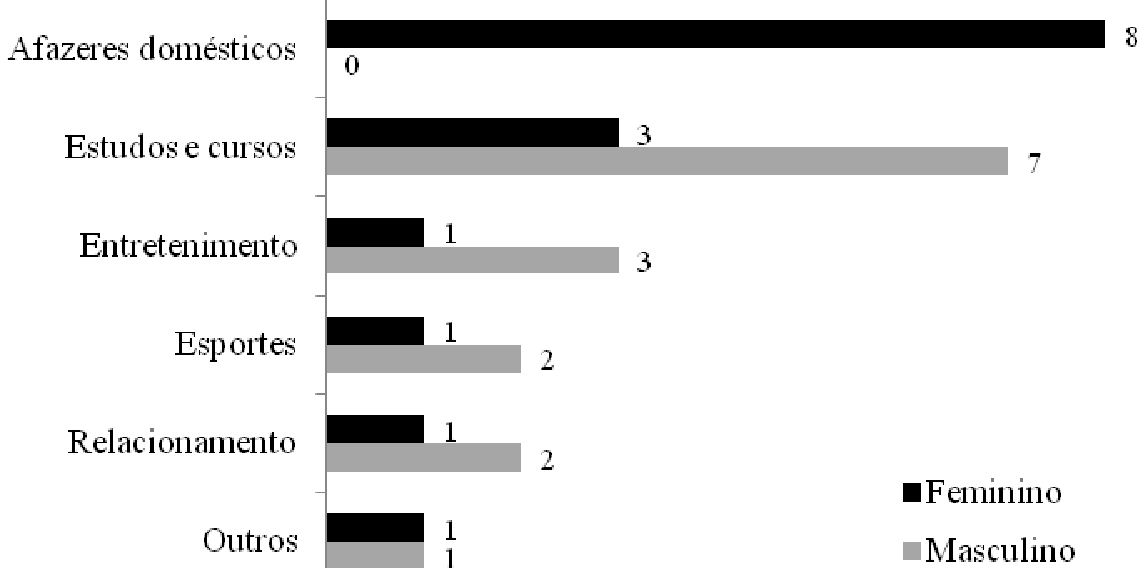

Fonte: Elaboração própria. 
Como podemos verificar, mais da metade das jovens do sexo feminino cita atividades relacionadas aos afazeres domésticos, enquanto grande parte dos jovens do sexo masculino aponta atividades relacionadas aos estudos e à realização de cursos de formação. Os relatos dos participantes, portanto, sugerem grandes diferenças nos processos de socialização e educação voltados para os jovens do sexo feminino e do sexo masculino.

Para Sastre et al. (1999), a discriminação por gênero encontra-se presente já no espaço escolar. A autora destaca que o modelo de ensino que herdamos tem suas raízes sustentadas em um momento histórico em que a mulher não estava associada à vida pública, lugar este antes ocupado somente pelos homens. Assim, as mulheres não desempenhavam trabalho remunerado, e acabavam sendo formadas para realizarem afazeres domésticos. Sastre et al. (1999) afirmam que, em plena contemporaneidade, alguns princípios desse modelo de escola permanecem, influenciando intensamente a formação dos sujeitos; nesse sentido, a escola limita-se a abrir suas portas à população feminina, mas ignora o fato de que o conhecimento selecionado e priorizado já traz, em si, uma diferenciação vinculada ao gênero.

Ainda com base nos dados, ressaltamos que, em comparação às jovens, há mais jovens do sexo masculino inseridos no mercado de trabalho, tendo sua renda própria, conseguindo conciliar trabalho e estudo. É o que demonstra o gráfico a seguir:

\section{Gráfico 2 - Jovens inseridos no mercado de trabalho, por sexo dos/as participantes.}

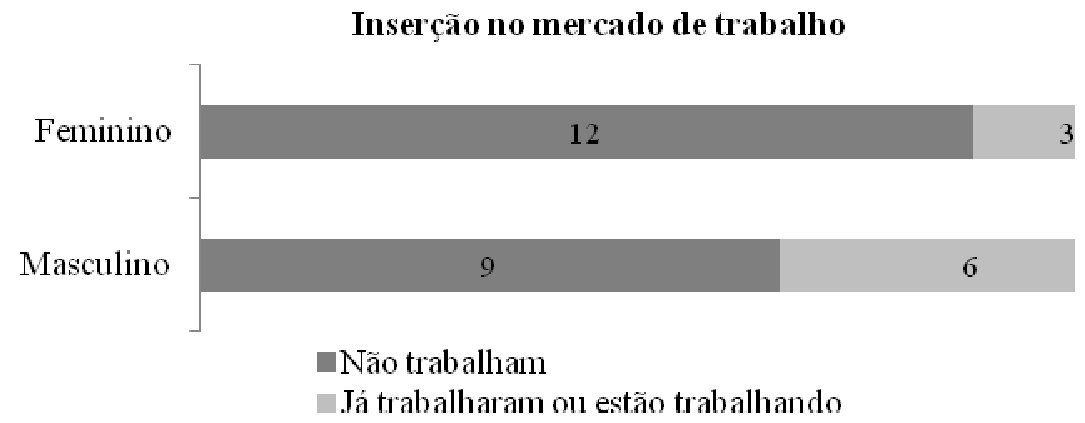

Fonte: Elaboração própria.

Quanto aos jovens do sexo masculino, os relatos indicam que estes parecem dispor de mais tempo para os momentos de lazer e liberdade para saírem à noite. Isso ocorre mesmo com aqueles que não estão inseridos nos trabalhos remunerados, ainda que auxiliem nos afazeres domésticos. Vejamos os fragmentos abaixo: 
[Você está trabalhando atualmente?] Estou. [Você já tinha trabalhado antes?] Eu trabalhava em mercado, trabalhei 3 anos. Desde os 14. [Você tem registro lá?] Tenho. [E você sempre trabalhou e estudou?] É, eu gosto. [Como é tua rotina?] Bom eu acordo, chego sempre atrasado no colégio, $7 \mathrm{~h} 35 \mathrm{~min}$ mais ou menos, chego em casa, almoço às $11 \mathrm{~h} 50$ mais ou menos, vou pro serviço, saio de casa $12 \mathrm{~h} 50$, vou de moto rapidinho, chego lá e começo, paro umas $15 \mathrm{~h} 30$ pra tomar um café, volto às $16 \mathrm{~h}$ e fico até às $21 \mathrm{~h} 30$. [Além de trabalhar e estudar, o que mais você faz?] Eu gosto de sair. Bastante. (Masculino, 17 anos).

De manhã eu venho pro colégio, estudo até meio dia. Saio, chego em casa, almoço, como eu não estou trabalhando, como eu falei, eu ajudo em casa. Umas 14 h eu vou ajudar minha mãe na casa, daí eu durmo até 14 h e depois ajudo ela. Quando tenho treino de futebol à tarde, às vezes começa 16h, então eu termino o serviço em casa e já vou pro treino. Quando não tem treino, depois que termino fico mexendo no computador, à noite eu saio, vou à casa dos meus amigos, andar. (Masculino, 16 anos).

Outro dado importante evidenciado em nossa análise é a preocupação das jovens do sexo feminino com os vínculos afetivos e com a constituição de uma família. As aspirações da jovem de 16 anos representam essa preocupação, enunciando o desejo da maternidade e a importância da presença da mãe no convívio e cuidado do filho: " $E u$ quero ter meus filhos, mas eu quero que meus filhos tenham pai, se não tiverem, pelo menos a mãe esteja ali pra cuidar". A este respeito, Sastre et al. (1999) mencionam que as relações entre os direitos e as obrigações que regulam a vida privada de homens e mulheres são bastante diferentes. Uma vez que é admitido inocentemente que os homens sejam menos capacitados para cuidar das relações interpessoais e a atenção para com os vínculos afetivos em que se sustentam os núcleos familiares, essa atividade acaba sendo direcionada à mulher que, muitas vezes, acaba sendo a única responsável por essa dimensão do cuidado.

A ênfase dada aos vínculos afetivos fica ainda evidenciada quando constatamos a diferença nos relatos dos jovens e das jovens no que compete à esfera do relacionamento amoroso. Vejamos o gráfico a seguir:

Gráfico 3 - Relacionamento amoroso comentado, por sexo dos/as participantes. 


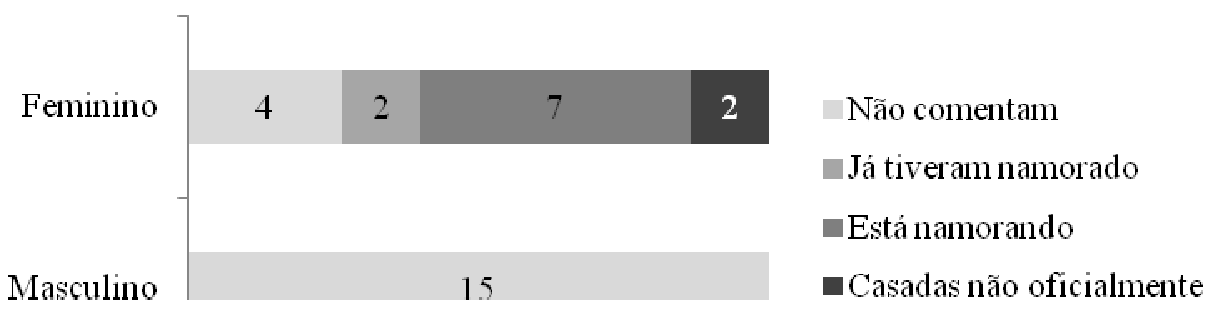

Fonte: Elaboração própria.

Como podemos verificar, enquanto a totalidade dos jovens masculinos deixa de comentar acerca dos relacionamentos amorosos, a maior parte das jovens do sexo feminino comenta sobre namoro e, inclusive, duas delas relatam já serem casadas. Esse dado demonstra, uma vez mais, o quanto a dimensão privada - das relações interpessoais e afetivas - faz-se relevante para as jovens do sexo feminino, mais do que para os jovens masculinos.

Os dados também nos permitem verificar diferenças de gênero refletidas nas expectativas de futuro dos jovens participantes. No gráfico a seguir, são apresentados os planos apontados pelos jovens e pelas jovens para os próximos 5 anos. Os dados foram tabulados tendo-se em vista a preocupação principal comentada pelo jovem na entrevista:

\section{Gráfico 4 - Planos para os próximos 5 anos, por do sexo dos/as participantes.}

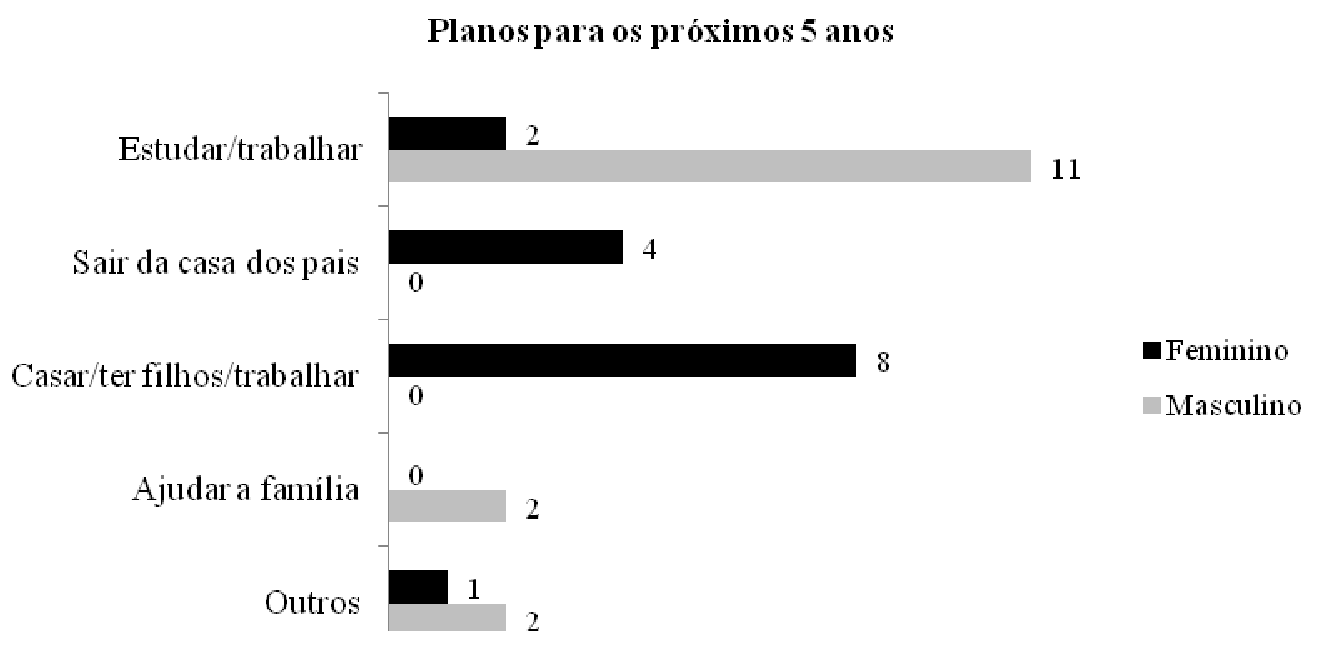

Fonte: Elaboração própria. 
A partir do gráfico acima, um dos pontos que chama a atenção é a quantidade de jovens que aponta, como plano para os próximos 5 anos, o desejo de sair da casa dos pais, aspiração citada apenas por participantes do sexo feminino. Acreditamos que esse anseio, em parte, pode ser reflexo da falta de liberdade para desfrutar de tempo para lazer e diversão. Os depoimentos abaixo explicitam esse desejo:

[Quero] sair de casa [você quer sair de casa e pra isso você tem que fazer o que?] Trabalhar... quando eu fizer 18 anos. [só pode trabalhar quando fizer 18 anos?] Não, posso trabalhar agora, mas não tem como, estou fazendo curso, estudando, vou arrumar um emprego pra ganhar 100 reais por mês, prefiro ficar em casa, pois só salário vai ser menos, mas o serviço é o mesmo, vai cansar, prefiro cansar em casa. (Feminino 16 anos).

[Planos para os próximos 5 anos?] Terminar meus estudos, começar uma faculdade, minha carteira de auto-escola, sair da casa de meus pais, porque vai ser difícil, mas se não for assim ficar debaixo só dos braços dos pais não vai dar certo, tem que preparar, o que não é fácil. Em cinco anos, acho que é isso. (Feminino, 15 anos).

Vejamos ainda outros depoimentos que apresentam os planos das jovens para os próximos 5 anos:

Eu quero estar morando sozinha, ter um meio de transporte, de preferência um carro, e queria ter um filho, mas eu não tenho vontade de ter um filho, eu tenho vontade de engravidar. (Feminino, 16 anos).

Casar, trabalhar e ter um bom emprego. (Feminino, 16 anos).

Tenho. De casar, fazer uma faculdade, só. (Feminino, 17 anos).

Daqui a 5 anos vou estar com 20. Daí vou estar casada, porque eu vou casar, como eu falei pra você. Então, acho que vou terminar de estudar, ter meu emprego, sei lá, qualquer coisa, estudar mais pra ter uma profissão. (Feminino, 15 anos).

Nos exemplos apresentados, a pretensão de construir família, ter filhos e casa própria são discursos recorrentes das entrevistadas. O trabalho e os estudos, embora apareçam, estão sempre associados à pretensão do casamento e da família. Cabe ressaltar que, em muitos casos, o desejo de casar e ter filhos reflete o modo que as jovens encontram de sair da casa dos pais, sugerindo uma vez mais um movimento de resistência diante da falta de liberdade que vivenciam. Nessa mesma direção, é importante ressaltar que é recorrente a manifestação por parte das jovens - mais do que no caso dos jovens de 
sexo masculino - do desejo de desempenharem atividades externas para terem seu próprio dinheiro e serem, de certa forma, autônomas.

Cabem, nesse momento, algumas ponderações acerca das possíveis implicações do casamento e da maternidade na vida das jovens, o que, em muitos casos, acaba implicando em seu distanciamento dos estudos e do mercado de trabalho. A este respeito, Sposito (2003) enfatiza que as responsabilidades tradicionais do trabalho doméstico feminino explicariam em parte o não acesso das mulheres jovens no mercado de trabalho e no sistema educacional. Em pesquisa realizada em 2001, a autora revela que, dentre os jovens que não estudam nem trabalham, a maioria estava situada nos extratos mais pobres. Quase metade dos homens estava procurando trabalho, enquanto $48 \%$ das mulheres já tinham construído família (muitas delas chefe de família) e 58\% já tinha filhos. Além disso, em muitos casos, as mulheres que ingressam no mercado de trabalho acabam recebendo salários inferiores aos dos homens no desempenho das mesmas funções. Assim, ressalta-se que as diferenças nas perspectivas de futuro dos jovens e das jovens não podem ser interpretadas apenas como uma opção ou uma preferência subjetiva, mas estão relacionadas a condicionantes vinculados ao gênero, e que podem dar origem a desigualdades que vêm se perpetuando ao longo das últimas décadas.

Diferente das perspectivas de futuro das jovens, os planos para os próximos 5 anos relatados pelos participantes do sexo masculino estão direcionados principalmente para o trabalho, o estudo e as aquisições materiais. Nos relatos de alguns jovens do sexo masculino, estudo e trabalho aparecem ainda como indissociáveis: é preciso estudar para ter um bom trabalho, e, mesmo que tenham dificuldades, pretendem conciliar estudo e emprego. Vejamos os trechos a seguir:

Terminar a escola, o Ensino Médio, trabalhar de dia e fazer faculdade à noite, de Ciências Contábeis. (Masculino, 16 anos).

Estudar, estudar e estudar, tentar entrar na faculdade e quando terminar a faculdade procurar um emprego, sossegado, e que possa me dar uma vida estável pra mim e pros meus pais. (Masculino, 17 anos).

Trabalhar e estudar. (Masculino, 15 anos).

Estudar muito. [O que mais?] Eu quero é estudar e ver, se der certo (porque nós estamos gravando já), eu quero gravar pelo menos um CD nesses 5 anos. (Masculino, 15 anos).

O que eu estou fazendo agora são cursos, de administração, de informática, de inglês... Tentando arrumar emprego, que dê pra comprar 
uma roupa, um calçado. Isso, no decorrer dos cinco anos. (Masculino, 15 anos).

Outro aspecto a ser destacado a partir dos dados é a responsabilidade assumida pelo jovem para com a família. No caso dos participantes, é frequente a preocupação dos jovens do sexo masculino em se colocar em uma atitude de ajudar financeiramente os pais, o que não ocorre nos relatos femininos. A seguir, o trecho apresentado evidencia a responsabilidade e preocupação da figura masculina na complementação da renda familiar, caso haja a necessidade:

\begin{abstract}
[Comente o que você imagina pro teu futuro? O que você quer e por $q u \hat{e} ?]$ Imagino tendo um trabalho bom, casa, carro e fazendo curso. [Você colocou que sua mãe é a coisa mais importante na tua vida, qual relação entre ela e seu projeto de futuro?] [...] pretendo ajudar ela [Faz parte de teus planos ajudá-la?] Sim [Ajudar como?] Financeiramente [Você vai ser responsável por isso?] Sim. [...] tem outro irmão, mas ele é bem mais novo. (Masculino, 15 anos).
\end{abstract}

Como podemos verificar, a vinculação dos jovens do sexo masculino ao âmbito público, do trabalho, acaba trazendo ao jovem a responsabilidade de manutenção financeira da família, em vista de complementar - ou, em muitos casos, de assumir na totalidade - a renda familiar. No entanto, cabe ressaltar que a preocupação dos jovens com sua família não expressa apenas a responsabilidade financeira atribuída tradicionalmente ao sexo masculino, mas revela também a importância dos vínculos afetivos para com seus pais e familiares. Assim, essa preocupação parece denotar a forma como os jovens do sexo masculino encontram para expressar suas relações no âmbito privado, o cuidado e o afeto que têm para com os pais e os irmãos. Essa responsabilidade e cuidado compreende não apenas a relação do jovem com seus pais, mas também sua relação na família que irá futuramente constituir:

[Por que esta preocupação com seu futuro?] Preocupação de que se eu tiver filhos, mulher e eu não puder dar um futuro bom para eles não vou me sentir bem. [Você acha que depende de você dar esse futuro bom para as pessoas que estivem contigo? Não tendo esta possibilidade te deixaria mal?] Bastante [Por quê?] Agora a mulher ajuda também, toda a vida foi o homem responsável, eu quero que a mulher trabalhe, mas quem vai cuidar das coisas de casa gostaria que fosse eu. (Masculino, 17 anos). 
Com base nas considerações já destacadas, podemos dizer que os relatos dos jovens participantes expressam o modo como os jovens reproduzem - e produzem significados vinculados ao gênero, a partir de suas vivências. Os relatos manifestam, ainda, as relações de poder e resistência vinculadas ao gênero, e que influenciam sobremaneira o modo como compreendem suas atividades, escolhas e projetos. Assim, as vivências dos jovens permitem-nos tecer considerações acerca das mudanças e permanências que se configuram nas relações contemporâneas. É possível identificarmos um exemplo das tensões entre tais mudanças e permanências nos relatos da jovem a seguir, em suas considerações acerca do casamento e expectativas de futuro. Há algumas décadas, o ideal considerado para mulher ao assumir o matrimônio era a permanência com o marido, mesmo sendo submissa a ele e, às vezes, sofrendo maus tratos. Atualmente, podemos verificar que as visões são outras. A jovem de 16 anos deixa transparecer que nem sempre o casamento é algo duradouro:

\begin{abstract}
[O que você considera como mais importante na sua vida?] A prioridade mesmo é me formar e fazer minha faculdade. [...] Em segundo lugar hoje, apesar de estar mais perto do que a faculdade, é o casamento que eu acho que no final do ano sai. [Por que você coloca a tua formação como sendo mais importante que o teu casamento e tua família?] Porque hoje sem estudo a gente não é nada e eu acho que eu tendo a minha faculdade, [...] é uma coisa que eu vou ser feliz e não tem preço que pague. Vendo assim, é uma coisa que daqui a um tempo, se eu chegar a casar e acabar separando, tendo meus filhos, eu vou ter meu dinheiro pra me sustentar, eu tenho meu diploma. (Feminino, 16 anos).
\end{abstract}

Para a jovem, sua autonomia no futuro mostra-se mais importante do que seu casamento, o qual, inclusive, pode não ser pra toda vida. Essa compreensão - que contraria o papel que em geral é atribuído à mulher, como vimos anteriormente - aparece simultaneamente à importância que a jovem atribui ao casamento religioso. Vejamos:

O meu namorado falou pra mim essa semana que ele vai me ajudar a conseguir o que eu quero, os meus objetivos, o meu pai falou pra mim que se eu casar agora eu vou perder tudo o que eu quero, então é meio complicado, eu não entendo muito os dois. [E quais são os sentimentos?] É uma coisa que eu quero, pra eu poder bater no peito amanhã e poder falar: Eu consegui. Uma coisa de conquista mesmo. Eu quero conquistar, quero ter o orgulho de mostrar que eu posso. $\mathrm{O}$ meu casamento é uma coisa mais de família. [...] Mas também é uma coisa de conquista. Eu quero bater no peito e dizer: Eu consegui, eu casei bonitinho. Eu vou ser a primeira a casar na igreja lá em casa. [Então esse é o sentimento?] É mais conquista. 
Ao que parece, para a jovem, o casamento é entendido a partir da relação de conquista, não se limitando somente a uma união amorosa e de escolha que lhe convém. Essa conquista quanto ao matrimônio, por sua vez, demonstra estar permeada de conflitos familiares, pois o pai classifica o casamento como um fator que pode trazer interferências negativas à perspectiva de futuro da filha. Ainda assim, o desejo de uma união oficializada perante os princípios religiosos ("vou ser a primeira a casar na igreja") parece ultrapassar qualquer barreira, fazendo com que ela sinta-se realizada.

Assim, notamos que, embora alguns valores e papéis sociais e culturais relacionados ao gênero venham se alterando, outros permanecem. Isso porque os significados são passados de geração em geração, influenciando os papéis a serem desempenhados por homens e mulheres e, em alguns casos, manifestando-se em diferenças - e desigualdades - de gênero presentes na sociedade contemporânea muito mais que imaginamos.

\section{Considerações Finais}

A partir do estudo realizado, pudemos verificar que as influências exercidas pelas diferenças de gênero ficaram evidenciadas nos relatos dos jovens entrevistados, apresentando em alguns casos uma desigualdade nas relações e na valorização das atividades almejadas e exercidas. Observou-se que os jovens, em seus depoimentos, trazem valores e representações que enunciam uma tendência à vida pública (estudo, emprego, trabalho, ou mesmo aquisição de bens materiais) pelos jovens do sexo masculino, e à vida privada (família, casamento, afazeres domésticos, relações interpessoais) pelas jovens do sexo feminino.

Os limites e possibilidades verificados na investigação denotam, em alguns casos, a visão androcêntrica e as relações de poder que constituem as relações de gênero (MORENO, 1999; SASTRE et al., 1999; VIANA; RIDENTI, 1998; SCOTT, 1994). No entanto, é possível perceber que as vivências dos jovens não apenas reproduzem as representações impostas pela sociedade, mas também sugerem novas possibilidades, ao expressarem preocupações, escolhas e resistências que, em alguns casos, contrariam, questionam ou problematizam os estereótipos e os valores estabelecidos.

Acreditamos que os limites e possibilidades que as diferenças de gênero trazem às vivências e expectativas dos jovens devem ser alvo de reflexões no contexto dos processos educativos voltados para a juventude, o que confere novas demandas em 
especial à escola, que se constitui como uma das esferas de influência na formação dos sujeitos. Diante das relações de desigualdade que se configuram a partir das diferenças de gênero, faz-se necessário o questionamento e a problematização de determinados papéis que são naturalizados de forma consciente e não-consciente pelos sujeitos.

Esperamos, por fim, que a pesquisa traga contribuições para a compreensão da juventude na contemporaneidade, e mais especificamente da influência das diferenças de gênero na socialização e educação dos jovens, o que poderá, em última instância, servir de base para reflexões acerca dos processos educativos voltados para as novas gerações.

\section{GENDER DIFFERENCES AND YOUTH: A STUDY FROM THE EXPERIENCES OF HIGH SCHOOL STUDENTS OF CAMPO MOURÃO, PARANÁ}

ABSTRACT: This text presents results of a research which aims to study youths' experiences, expectations, goals and choices and the possible evidences of gender differences and inequalities. Semi-structured interviews were conducted with 30 youth students (15 to 17 years). Data analysis shows influences exerted by gender differences in the narratives of youths, stating values and practices that emphasized the public dimension for the male youths and the private sphere for female youths. Based on results, some considerations are made about educational processes directed to youth.

KEYWORDS: Youth. Gender. Educational processes.

\section{REFERÊNCIAS}

ARANTES, V.; SASTRE, G.; GONZÁLEZ, A. Violência contra a mulher e representações mentais: um estudo sobre pensamentos morais e sentimentos de adolescentes. Psicologia: Teoria e Pesquisa, Brasília, v.26, n.1, p.109-120, jan./mar., 2010.

FUKUDA, C. C.; BRASIL, K. T.; ALVES, P. B. Fatores de risco e proteção: considerações sobre gênero. In: LIBÓRIO, R.; KOLLER, S. Adolescência e juventude: risco e proteção na realidade brasileira. São Paulo: Casa do Psicólogo, 2009. p.107-131.

LUZ, L.; PÁTARO, C. S. Diferenças de gênero na juventude: Um estudo a partir das vivências de estudantes de ensino médio do município de Campo Mourão. Revista NUPEM, Rio de Janeiro, v.2, n.3, p.215-222, 2010.

MORENO, M. Como se ensina a ser menina. São Paulo: Moderna; Campinas: Ed. da UNICAMP, 1999.

MORENO, M. et al. Conhecimento e mudança: os modelos organizadores na construção do conhecimento. São Paulo: Moderna; Campinas: Ed. da UNICAMP, 1999. 
PÁTARO, C. S. Sentimentos, emoções e projetos vitais da juventude: um estudo exploratório na perspectiva da Teoria dos Modelos Organizadores do Pensamento. 2011. 232f. Tese (Doutorado em Educação) - Universidade de São Paulo, São Paulo, 2011.

PÁTARO, C. S. Dimensão afetiva e projetos vitais de jovens estudantes de ensino superior. Revista Educação, Rio Claro, v.22, p.28-42, 2012.

PÁTARO, C. S.; ALMEIDA, F. Afetividade e juventude: um estudo sobre os sentimentos e emoções a partir da representação de jovens estudantes. Psicopedagogia On Line, [S.1.], n.1, p.1-15, 2011. Disponível em: <http://www.psicopedagogia.com.br/new1_artigo.asp?entrID=1370>. Acesso em: $10 \mathrm{dez}$. 2013.

PERALVA, A. T.; SPOSITO, M. Editorial. Revista Brasileira de Educação, Rio de Janeiro, v.5, n.6, p. 3-4, mai./dez., 1997.

QUEIROZ, M. I. P. Relatos orais: do "indizível" ao "dizível". In: VON SIMSON, O. M. Experimentos com histórias de vida: Itália - Brasil. São Paulo: Vértice, 1988. p.14-43.

SASTRE, G. et al. Falemos de sentimentos: a afetividade como um tema transversal. São Paulo: Moderna; Campinas: Ed. da UNICAMP, 1999.

SCOTT, J. Prefácio à Gender and politics of history. Cadernos Pagu, Campinas, n.3, p.11-27, 1994.

SPOSITO, M. P. Os jovens no Brasil: desigualdades multiplicadas e novas demandas políticas. São Paulo: Ação Educativa, 2003.

STACH-HAERTEL, B. A constituição das subjetividades legitimadoras das desigualdades de gênero. 2009. 176f. Dissertação (Mestrado em Educação) Universidade de São Paulo, São Paulo, 2009.

VIANNA, C.; RIDENTI, S. Relações de gênero e escola: das diferenças ao preconceito. In: AQUINO, J. G. (Org.). Diferenças e preconceito na escola: alternativas teóricas e práticas. São Paulo: Summus, 1998. p.93-105. 